\title{
Perspectives for improving management speech communication and system organization of construction in the digital economy
}

\author{
Tatiana Bagdasaryan, Olga Kljuchnikova*, and Lev Melnikov \\ Don State Technical University, 344000, Rostov-on-Don, Russia
}

\begin{abstract}
The active introduction of digital technologies has an impact on the development of all sectors of the economy. The implemented technologies determine the development of public administration and business, the formation of new forms of communication in society, which creates a synergistic effect as a result of the digitalization of the economy, both in Russia and in the world. The article considers the directions of technological and information support of the construction industry in the digital economy. Based on the analysis, it is assumed that the digitalization of the company's activities in the construction industry, taking into account the trends of the digital economy, will increase the competitiveness in the industry and the economic efficiency of the activity as a whole.
\end{abstract}

\section{Introduction}

The issues of the region's transition to an effective digital economy are the most important strategic issues of science and technology. The modern concept team management actualizes such important function as communication. Speech is one of the leading points in management information in the face of negative environmental factors and is one of the main influencing tools in the management of society and the economy as a whole. As a result of such a negative factor, the negative phenomena that appear in speech have a destructive effect on the employee of the team, as well as on the results of his work and the final economic basis. The use of combined management systems based on BIM technologies involves the involvement of many participants in the production process, communicating with each other. In this regard, the issue of updating eco-friendly and effective communication management of production is particularly relevant

The scientific hypothesis is that effective online construction management is possible. Organizational decision-making and effective communication in decision-making process among participants of one team are also possible [1].

Formation of modern para-metrological schedules of work production, which involve taking into account the terms and their adjustment, the sequence and volume of work

${ }^{*}$ Corresponding author: aristova1984@mail.ru 
performed at the construction stages in a remote automated mode [1,2]. The schedules of the original project are processed and adjusted by the general contractor, based on the reality of construction, which often causes an irrational use of time and resources. The introduction of automated systems for remote monitoring and examination of the building under construction allows to optimize this procedure and avoid subjective organizational decisions in construction. At the same time, participants in investment and construction activities are in the same communicative sphere, but, taking into account the factors of globalization and internationalization of business solutions, they can speak different languages and have different communicative competence, which is going to be discussed in detail below [2-3].

\section{Materials and methods}

This article deals with the construction management buildings or several objects, which are under the management of one organization with international representative offices.

All basic information on buildings under construction is entered into the automated object management system. The initial information indicates the preference of objects by the degree of importance for the estate developer, the timing of commissioning, etc. Objects are structured according to horizontal and vertical links by the degree of development:

- horizontal links - according to the degree of readiness and the stage of work on the objects in the organization;

- vertical - for work at each stage of construction of the underground and aboveground parts of the building[4-6].

The output graphs automatically calculate and indicate the daily resource consumption for each job and the resulting total intensity of use of this type resource in the whole task, as well as the amount of free balance or resource deficit. In addition, the time parameters of all works as of the end of the reviewed period are given.

Calculation and issuance of the weekly and monthly plan for a single portion of the source data for a separate object and the entire system is performed without human intervention, the operator only enters the source data into the system:

1. Technological stage

2. Data at the beginning of the period

3. Control level of resource consumption

4. Control level of balances

5. The planned execution rate.

Thus this minimizes the involvement of the foreman in documented procedures and increases the clarity of resource use. Expert audit control is carried out immediately at a given technological stage, without diverting additional resources to the preparation and with the maximum possible objectivity of the construction analysis as a whole and the specific audit stage [7]. However, even at the stage of audit control, communication difficulties may arise among control participants and performers of the work due to their language barrier [8-10]. 


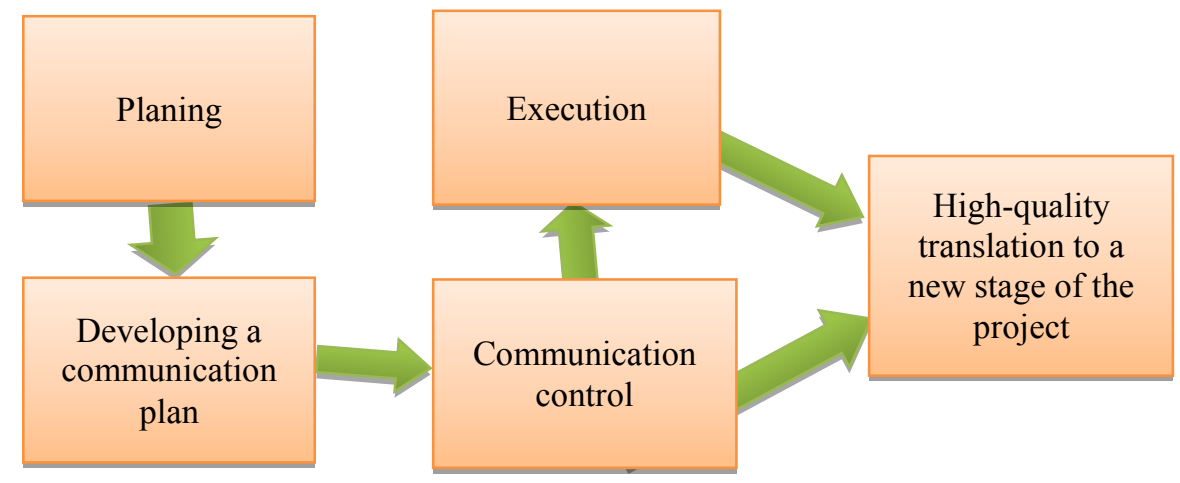

Fig. 1. The scheme of the company's communication algorithm. Author's development

\section{Results}

It is no secret that in the modern construction industry, the practice of attracting workers from among labor immigrants is widely used. Savings in wages, social guarantees and health insurance often lead to such problems as increased construction costs, delays in the completion of work, as well as their poor quality due to the presence of communication barriers between participants in the construction industry.

These barriers include:

- language barrier - participants in the construction industry speak different languages;

- cognitive - participants do not understand each other due to differences in educational or linguistic-cultural level;

- complex - participants experience communication difficulties due to the influence of both factors.

It seems that the use of modern information technologies at the stage of planning, organization and management of construction will reduce these risks and ensure the integration of participants into a single cognitive and communicative space. This is possible through the introduction of intelligent translation tools and integrated web dictionary platforms. From the organizational and technological point of view, the improvement of the management and communication component is implemented as follows. The calendar plan is the technological basis for determining the main indicators of the monthly work plan of the object and the construction complex as a whole [3]. Its control does not involve timeconsuming and lengthy manual calculation (in MS Project environments, etc.) of indicators (estimated cost, labor intensity, salary fund, etc.). All these control stages are also integrated into the automated control system. The transfer from contractor to contractor is carried out as part of the completion of a whole technological stage, for example, from the preparation of the building frame to the installation of enclosing structures. At the same time, quality control is carried out by both the receiving contractor and an independent expert on the part of the developer. The examination is carried out without stopping production using integrated systems for evaluating deadlines, volumes, and resources according to the reporting system entered in the databases of all participants in the process, as well as visual and instrumental methods, reporting on which is also recorded in the database and processed in the automated control system [8-10].

To automate the calculation of planned indicators, a control set is used using a constant array. They were developed at the design stage of the control and measurement indicators. Their compliance is an indicator of product quality. The comparison is made with the 
participation of the operator, but with a high degree of automation. The control parameters are compared by a range of indicators and the operator is provided with information about compliance for making an expert organizational decision. Accounting is conducted for 24 main types of materials: rebar of all classes, brick, wood, glass, etc. (according to the existing regulatory documentation).

Any characteristic of the work (part of it) performed during the planned period (estimated cost, volume, salary fund, need for materials, delivery, inventory, expense) is defined as the product of the labor intensity of its performance by the corresponding coefficient. The characteristics of individual works are co-operated in the project databases. The weekly-daily schedule is coordinated by work, supplies, costs, inventory, and expert organizational decisions [11-14].

\section{Discussion}

We see an example of this kind of work organization in one of the largest construction companies in China - China State Construction Engineering[15].

The introduction of an automated planning system with the issuance of monthly weekly and daily plans allows a company that conducts construction both in China and abroad (for example, the construction of some terminal facilities in the ports of the Baltic States) to correct all inaccuracies in the source data and conduct remote monitoring of projects from offices located geographically in China in real time.

According to the decisions made, plans developed on the basis of complex schedules are modeled for a time of no more than a month for the early start of work, and for objects where the installation of frames (a stereotypical type of work on objects) had significant time reserves, deliveries are attributed to a later date.

Further study of acceptable risk levels for all participants in the investment and construction process allowed us to develop a grading scale (Table 1).

Table 1. Example of an organizational and technological model of work and resources

\begin{tabular}{|c|c|c|}
\hline $\begin{array}{c}\text { The value of the } \\
\text { indicator } \mathrm{R}\end{array}$ & $\begin{array}{c}\text { The acceptability of the } \\
\text { level of risk for investors in } \\
\text { the construction industry }\end{array}$ & $\begin{array}{c}\text { Recommendations for the } \\
\text { implementation of an } \\
\text { investment and construction } \\
\text { project (portfolio) }\end{array}$ \\
\hline $\mathrm{R}>50 \%$ & The risk is not acceptable & $\begin{array}{c}\text { Complete rejection of the } \\
\text { implementation }\end{array}$ \\
\hline $30 \%<\mathrm{R}<50 \%$ & $\begin{array}{c}\text { Implementation is possible } \\
\text { only after the development } \\
\text { of drastic measures to } \\
\text { reduce the level of risk and } \\
\text { its re-assessment }\end{array}$ \\
\hline $15 \%<\mathrm{R}<30 \%$ & The risk is relatively \\
acceptable & $\begin{array}{c}\text { Possible implementation } \\
\text { when forming an aggressive } \\
\text { portfolio, taking into } \\
\text { account the implementation } \\
\text { of measures to prevent an } \\
\text { increase in the level of risk }\end{array}$ \\
\hline $5 \%<\mathrm{R}<15 \%$ & $\begin{array}{c}\text { The risk is acceptable for } \\
\text { the construction industry in } \\
\text { Russia }\end{array}$ & $\begin{array}{c}\text { Mandatory implementation } \\
\text { of measures to monitor the } \\
\text { level of risk }\end{array}$ \\
\hline
\end{tabular}




\begin{tabular}{|c|c|c|}
\hline $\begin{array}{c}\text { The value of the } \\
\text { indicator } \mathrm{R}\end{array}$ & $\begin{array}{c}\text { The acceptability of the } \\
\text { level of risk for investors in } \\
\text { the construction industry }\end{array}$ & $\begin{array}{c}\text { Recommendations for the } \\
\text { implementation of an } \\
\text { investment and construction } \\
\text { project (portfolio) }\end{array}$ \\
\hline $\mathrm{R}<5 \%$ & $\begin{array}{c}\text { The risk is completely } \\
\text { acceptable }\end{array}$ & \\
\hline
\end{tabular}

The delivery schedules and statements adjusted in this way are approximated and brought into line with the construction deadlines at remote sites in compliance with quality measures and product compliance with legal requirements.Delivery schedules have been adjusted to meet construction deadlines at remote sites. The quality was observed and the products meet the requirements of the legislation. The delivery process is monitored both on-site and remotely. All this is planned by the center for the constructing complex.The complex management can constantly monitor the state of supply resources, as well as technological, lifting, transport and energy equipment, wear and tear and the degree of mechanization of each stage. The information that is promptly issued by the planning center is accurate. Therefore, the control over the supply of resources is reliable and effective.

The heads of the complexes are granted the rights of deputy managers of the company. Chief engineers of the main installation organization and deputy directors of construction companies were appointed as deputy heads of the complexes. This structure made it possible to quickly resolve all issues that arise during the construction process. Organizational preparation for construction is made out by a joint order for the entire project and the customer on the construction of facilities or complexes according to network schedules. The specified order defines the composition of operational dispatch groups, the timing of the start of the system, the collection of information, the conduct of operational on-lain meetings, the procedure for forming operational urgent work plans.

Operational dispatch groups are organized at the complexes, which receive information from work performers, analyze and adjust schedules, transmit information to computers, receive processed information, make reference analyses of the construction progress, keep a map of the work, prepare minutes of operational meetings, prepare operational work plans, etc. The project activities are regulated by the "Instructions for the organization of operational planning of works and deliveries and construction control to network schedules based on the software package for computer systems".

Operational dispatch groups at construction complexes are equipped with subscriber access to the unified information and planning system for managing the construction project.

Sustainable performance indicators for the commissioning of production facilities are achieved as a result of carefully designed organizational and technical measures, management of construction production, effective control of the implementation of decisions made according to the developed plan with a comparison of the results with the BIM model of the object.

Experience has shown that the head of a construction organization should have such data that will not only allow, but also make you know the actual state of construction and take the necessary measures in a timely manner to prevent lagging behind schedule.

Such data is contained in the "Signal Schedule", developed in the complex of information support for construction.

Once a week, in the presence of the heads of departments and the customer, the information of the operational dispatch group on the progress of work in the complex is reviewed and the necessary decisions are made.

The following eight groups were identified for the weekly analysis of the reasons for the backlog of deliveries and the completion of work from the schedule: 
1) late delivery of the main equipment;

2) late delivery of non-standardized equipment and materials by the customer;

3) late delivery of metal structures and semi-finished products;

4) improper organization of construction works and lack of provision of construction materials, transport and machinery;

5) improper organization of installation works and lack of supply of their materials;

6) untimely performance of previous works by a related contractor;

7) late correction of previously issued drawings and plans;

8) various unforeseen circumstances

A cyclogram was constructed, where delays and timely elimination of them are presented in percentages, taking into account the use of an automated remote control system

\section{Conclusion}

Thus, due to the rapid monitoring and signaling of emerging delays, as well as timely decision-making, only in less than $9 \%$ of cases, it took more than a day to eliminate delays. In fact, information about the likely delay was received by the planning center in advance, a day or more before it occurred. The management team had enough time to eliminate the possible backlog of deadlines, to ensure the implementation of the work schedule.

It should be noted that the head office of the company in China has done a great job in implementing the communicative unity with the representative offices in the development areas. English has been adopted here as an international and intra-company language of communication. However, all management decisions were processed not only by translation into English, but also adapted to the possibilities of implementation by the performers. Not only the linguistic skills of the employees were taken into account, but also the international nature of their actions. The linguistic and cultural basis of Chinese managers was integrated into the transnational unity of Russian-speaking engineers, as well as workers who come from the Baltic countries or Turkish-speaking performers of working specialties. Modern capabilities of information systems have made it possible to attract specialists in the field of linguistics and intercultural communication and synchronize their work in such a way as to ensure optimal managerial communication of transnational construction. Thus, the use of remote automated control and management systems proves its reliability and timeliness of real estate construction management.

\section{References}

1. J. Čamaj, J. Mašek, M. Kendra, Procedia Engineering 134224, 230 (2016). doi: 10.1016/j.proeng.2016.01.063

2. D.S. Anderson, Lang. Educ. $25 \quad$ (4), 273-289 (2011). doi:10.1080/09500782.2011.577218

3. M.De Meulder, A. Kusters, E. Moriarty, J.J. Murray, Multicult. Dev. 2 (2), 1-15 (2019). doi:10.1080/01434632.2019.1592181

4. P. Garrett, Cambridge Univ. Press, Cambridge, UK (2011). doi:10.1017/CBO9780511844713

5. B. Abramović, D. Šipuš, Springer International Publishing, 86-96 (2020). doi:10.1007/978-3-030-19519-9_2

6. A. Kusters, Lang. Soc. 43 (2), 139-158 (2014). doi:10.1017/S0047404514000013 
7. L. Guiso, P. Sapienza, L. Zingales, Jour. Fin. Econ. 117 (1), 60-76 (2015). doi: 10.1016/j.jfineco.2014.05.010

8. J. Safar, O. Le Guen, G. Collí Collí, Hau M. Collí, Sign Lang. Stud. 18 (4), 488-516 (2018). doi:10.1353/sls.2018.0014

9. Sallabank J. Multilingua 38 (2018). doi: 10.1515/multi-2018-0002

10. A. Kusters, M. Spotti, R. Swanwick, E. Tapio, Int. J. Multiling. 14 (3), 219-232 (2017). doi:10.1080/14790718.2017.1321651

11. T.B. Mikheeva, E.V. Murugova, SHS Web of Conf (2019). doi.org/10.1051/shsconf/20197007003

12. S.V. Pervukhina, O.A. Evtouchenko, L.Iu. Kotliarenko, M.P. Churikov, SHS Web of Conferences. Curr. Iss. Mod. Ling. Hum. 232-244 (2020). doi: $10.1051 /$ shsconf $/ 20208801013$

13. M.A. Tamarkin, A.N. Isaev, E.V. Murugova, V.I. Butenko, MATEC Web of Conf. (2018). doi:10.1051/matecconf/201822601025

14. S. Pervukhina, V. Demchenko E3S Web of Conf. (ITSE 2020). 18033. doi:10.1051/e3sconf/202021018033

15. N.B. Boeva-Omelechko, M.R. Zheltukhina, O.P. Ryabko, G.G. Matveeva, E.V. Murugova, I.A. Zyubina, Space and Culture, India 4, 112-121 (2018). doi: 10.20896/saci.v6i4.387 